\title{
Medical Gas Supply Problem
}

National Cancer Institute

\section{Source}

National Cancer Institute. Medical Gas Supply Problem. NCI Thesaurus. Code C72887.

Problem associated with the facility-supplied medical gases such as medical air, oxygen, nitrous oxide, and nitrogen. 